\title{
The production of Italian dental affricates by Portuguese speakers
}

\author{
Chiara Meluzzi \\ Department of Linguistics, University of Pavia, Italy \\ https://doi.org/10.36505/ExLing-2020/11/0032/000447
}

\begin{abstract}
This work deals with the production of Italian dental affricates / ts dz/ by 2 female Portuguese speakers. Due to the lack of affricates in their L1, the aim was testing whether an affricate articulation and lengthening is preserved across phonological contexts. Through sentence-list reading, it will be shown how the affricate articulation is generally preserved, although /dz/ tends to reduce into a fricative / $\mathrm{z} /$ more than the voiceless /ts/. An intermediate degree of sonority has also been detected together with a peculiar lengthening of the affricate involving only the occlusive part, whereas the fricative remains unvaried. These results may indicate a different phonological status of dental affricates for LS speakers.
\end{abstract}

Keywords: dental affricates, language acquisition, phonetics, Italian.

\section{Italian dental affricates: L1 and LS}

Dental affricates are considered typologically rare and marked sounds (Maddieson 1984). These sounds are difficult to be perfectly acquired by L2 or LS speakers (cf. Costamagna 2008, Sorianello 2019). In particular, the voiced $/ \mathrm{d} z /$ tends to be substituted with the fricative counterpart /z/ and/or to loss voicing, partially or completely. This also reflects the evolution of voiced affricates in the phonological repertoires of many languages ( $\dot{Z}$ ygis 2008: 23).

Italian has preserved a phonological opposition between voiceless and voiced dental affricates, but with a great variation within Italian dialects (cf. Meluzzi 2020: 43). Detailed phonetic analysis of Italian L1 speech has highlighted the emergence of an intermediate sonority degree, in which voicing is only present in the occlusive part. The emergence of this third degree of sonority has been identified in Italian native speakers in particular sociophonetic settings, such as in dialect-contact situations (cf. Meluzzi 2020). Conversely, Portuguese phonology does not present affricates, with the partial exception of post-alveolars in loanwords.

This work offers a preliminary analysis of the phonetic variation in terms of voicing and lengthening of dental affricates as produced by two Portuguese speakers. The hypothesis is that these sounds will be reduced into fricatives, and that they will differ from L1 in both voicing and lengthening.

ExLing 2020: Proceedings of $11^{\text {th }}$ International Conference of Experimental Linguistics, 12-14 October 2020, Athens, Greece 


\section{Methodology}

Two 35 y.o. female speakers have been recorded in a sound-proof room at University of Pavia in different moments. They came from the same town in Portugal, and were living in Northern Italy since 5 years at the moment of recordings. They did not receive a formal education in Italian, although they engage regularly with Italian friends.

Speakers were asked to read twice a list of 52 Italian realistic sentences, each one containing a real word with a dental affricate in different phonological constraints, and an equal number of distractors. The sentences were all declaratives with a balanced prosodic contour (e.g., C'è un pazzo sulla strada, "There's a mad man on the road"). Among the 52 stimuli, 18 tokens presented the dental affricate in intervocalic geminated contest, 8 in singleton, 10 as wordinitial and 16 after a sonorant $/ 1 /-/ \mathrm{n} /-/ \mathrm{r} /$. The distribution of tokens aimed at mirroring the phonological distribution of dental affricates in the Italian lexicon. The total 212 tokens were manually annotated in PRAAT following Meluzzi's (2016, 2020) protocol. Affricates were classified as either voiced, voiceless or intermediate, according to the presence of the voicing bar; the presence of a gap between the occlusive and fricative part was also annotated.

\section{Analysis}

The analysis was conducted from both a qualitative and a quantitative perspective. Qualitatively, different phenomena have been noted such as: (1) difficult in maintaining vocal folds vibration through the whole phone; (2) presence of a gap between the occlusive and the fricative portion; (3) different length of the occlusive and the fricative portion across phonological contexts.

Affricates tends to be reduced to fricatives in about the $30 \%$ of the cases $(20$ cases for $/ \mathrm{ts} />/ \mathrm{s} /, 42$ for $/ \mathrm{dz} />/ \mathrm{z} /$ ); this frication is not determined by the phonological context. As in native speech, the distribution of sonority of dental affricates is determined by the phonological context (cf. Fig. 1): intermediate realizations appear more in intervocalic contexts, both geminate and singleton. Finally, voiced affricates in post-sonorant and geminate contexts also present a partial limitation of vocal fold vibration.

A difference in duration of the dental affricates and of the occlusive portion has also been found as determined by the phonological context. Conversely, the fricative portion of the affricate stays unvaried across contexts. Intermediate affricates do not vary across phonological contexts. 


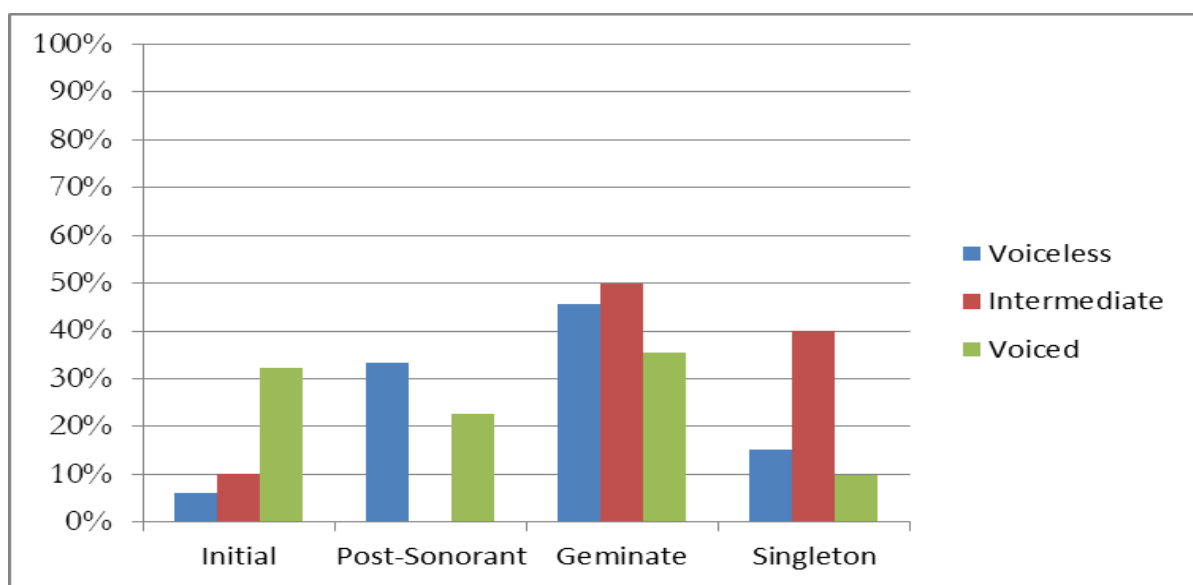

Figure 1. The realization of dental affricates as voiced, voiceless or intermediate according to the phonological contest $\left(\chi^{2}(6)=15,083, p=, 02\right.$, Cramer's $\left.V=, 319\right)$

Table 1. Duration of voiced and voiceless dental affricates across phonological contexts (ANOVA: /ts / F(3,29)=7,612, $\mathrm{p}=, 001 ; / \mathrm{dz} / \mathrm{F}(3,29)=2,721, \mathrm{p}=, 006$ ).

\begin{tabular}{l|llll}
\hline & Initial & Post-Sonorant & Geminate & Singleton \\
\hline /ts/ & $185,75 \mathrm{~ms}$. & $134,62 \mathrm{~ms}$. & $212,51 \mathrm{~ms}$. & $230,16 \mathrm{~ms}$. \\
& (st. dev. 10,8) & (st. dev. 4,58) & (st. dev. 4,37) & (st. dev.27,77) \\
$/ \mathrm{dz} /$ & $136,86 \mathrm{~ms}$. & $96,38 \mathrm{~ms}$. & $166,03 \mathrm{~ms}$. & $160,03 \mathrm{~ms}$. \\
& (st. dev. 5,06) & (st. dev. 4,32) & (st. dev. 5,86) & (st. dev. 4,98) \\
\hline
\end{tabular}

Tab. 2. Duration of the closing portion of voiced and voiceless dental affricates across phonological contexts (ANOVA: /ts / $\mathrm{F}(3,29)=6,497, \mathrm{p}=, 002 ; / \mathrm{dz} /$ $\mathrm{F}(3,29)=7,802, \mathrm{p}=, 001)$.

\begin{tabular}{l|llll}
\hline & Initial & Post-Sonorant & Geminate & Singleton \\
\hline /ts/ & $72,47 \mathrm{~ms}$. & $34,27 \mathrm{~ms}$. & $74,49 \mathrm{~ms}$. & $64,9 \mathrm{~ms}$. \\
& (st. dev. 2,8) & (st. dev. 1,51) & (st. dev. 2,92) & (st. dev. 1,69) \\
/dz/ & $51,55 \mathrm{~ms}$. & 21,14 ms. & 64,98 ms. & $46,11 \mathrm{~ms}$. \\
& (st. dev. 2,18) & (st. dev. 7,47) & (st. dev. 2,81) & (st. dev. 1,05) \\
\hline
\end{tabular}

The data in Tab. 1 shows how voiced affricates are always shorter than voiceless ones. No great difference occurs between the two intervocalic contexts, whereas affricates are sensibly shorter in post-sonorant context, also confirmed by the post-hoc Tukey test. In voiced affricates, the occlusive portion is shorter in singleton and post-sonorant contexts as opposed to geminate one. For the voiceless affricates, however, the data confirms a similarity between the two intervocalic contexts vs. the post-sonorant one. 


\section{Discussion}

Contrary to previous study, our data shows that non-native Italian speakers reduces affricates into fricatives less frequently than expected, although a major difficulty is attested with the voiced affricate $/ \mathrm{dz} /$. The emergence of an intermediate sonority degree as also been attested. The similarity in durations of singleton and geminate affricates mirror the productions of native speakers, in which a general opposition has been found between intervocalic vs. postsonorant contexts. What appears to be typical of non-native speech is that the lengthening processes affect only the occlusive part of the affricate, leaving the fricative unvaried in duration across contexts.

These data could indicate that for non-native speakers the affricate articulation is differently interpreted at a phonological level: more than a proper phoneme, affricates could have been interpreted as a sequence of an occlusive and a fricative. This explanation could also account for the presence, albeit randomly attested in our data, of a gap between the closure and the frication.

\section{Conclusions and further perspectives}

This preliminary study on the production of Italian dental affricates by Portuguese speakers has confirmed how dental affricates are complex sounds, easily to be acquired by non-native speakers. The different lengthening patterns highlighted indicated that the phonological status of dental affricates may be different in L2/LS with respect to Italian L1. Due to the limits of our speech sample, it appears evident that further research on the phonetic characteristics of Italian dental affricates are needed in order to ascertain their phonological status in particular in L2 speech. It will also be interesting to correlate different phonetic features with the perception of a "foreign" accent.

\section{References}

Costamagna, L. 2007. The acquisition of Italian L2 Affricates: the Case of a Brazilian Learner. Proceedings of the congress 'New sounds', 26-29.

Maddieson, I. 1984. Patterns of Sounds. Cambridge: Cambridge University Press.

Meluzzi, C. 2016. A New Sonority Degree in the Realization of Dental Affricates / ts dz/ in Italian. In Ball, M.J. \& Müller, N. (eds.), 2016, Challenging Sonority. Crosslinguistic Evidence, 252-275. Lodon: Equinox.

Meluzzi, C. 2020. Sociofonetica di una varietà di koinè. Le affricate dentali nell'italiano di Bolzano. Milano, Franco Angeli. Open Access: http://ojs.francoangeli.it/_omp/index.php/oa/catalog/book/459

Sorianello, P. 2019. Le consonanti affricate: strategie di acquisizione in italiano L2, Italiano LinguaDue 11.1, 1-21.

Żygis, M. 2008. On the Avoidance of Voiced Sibilant Affricates. ZAS Papers in Linguistics 49, 23-45. 